\title{
Construction Scenario for a Rural Tourism Value Chain: A Case Study from Rural China
}

\author{
Liaoji Zheng ${ }^{*}$, Huanyu Wang1, Gang Li², Yiyan Guo ${ }^{3}$ \\ ${ }^{1}$ School of Management, Eastern Liaoning University, Dandong, China \\ ${ }^{2}$ School of Design, Eastern Liaoning University, Dandong, China \\ ${ }^{3}$ School of Agriculture, Eastern Liaoning University, Dandong, China \\ Email: *zhengliaoji@vip.sina.com
}

How to cite this paper: Zheng, L. J., Wang, H. Y., Li, G., \& Guo, Y. Y. (2021). Construction Scenario for a Rural Tourism Value Chain: A Case Study from Rural China. American Journal of Industrial and Business Management, 11, 1-18.

https://doi.org/10.4236/ajibm.2021.111001

Received: December 7, 2020

Accepted: January 9, 2021

Published: January 12, 2021

Copyright $\odot 2021$ by author(s) and Scientific Research Publishing Inc. This work is licensed under the Creative Commons Attribution International License (CC BY 4.0).

http://creativecommons.org/licenses/by/4.0/ (c) (i) Open Access

\begin{abstract}
Value chain is the value-added process resulting from the extension of rural tourism industry chain. Its direction of construction includes the extension of the vertical service field, and the combination of horizontal rural regional elements. The tourism value chain (TVC) is closely related to the transformation of the value elements of rural production, life, ecology, and culture, which helps to promote the high-quality development of rural tourism and the implementation of rural construction in China. Using Dalishu village as an example, this study applied a cross-impact balance analysis (CIB) to select the scenario of the rural TVC. The best scenario of TVC includes the basic value activities and auxiliary value activities of life, industry, ecology, society, and ecology. The optimal scenario results from selections that maximize the leading role of value elements. The scenario of the selected TVC reflects the personalized characteristics of the rural tourism destination, maximizing the leading role of key value elements, and advances the coupling and linkages between rural tourism and rural development.
\end{abstract}

\section{Keywords}

Tourism Value Chain (TVC), Scenario, Cross-Impact Balance Analysis (CIB), Dalishu Village

\section{Introduction}

The world tourism has grown significantly over the past three decades, bringing significant benefits to all participants in the tourism value chain (TVC). The concept of the value chain was first proposed by Michael Porter, an American scholar (Porter, 1985). It refers to the activities associated with increasing the internal and external value of industrial enterprises, which helps to assess the 
competitiveness of local tourism products and focus on local economic development (Adiyia, Stoffelen, Jennes, Vanneste, \& Ahebwa, 2015). As a new form of multifunctional agricultural production division, the rural TVC not only describes the "fragmentation" phenomenon of vertical separation of various links in the production of tourism products, but also contains the spatial distribution relationship between high value-added links and low-value-added links. It represents a series of value-added activities that are composed of basic value activities, auxiliary value activities, and co-creating value activities ( $\mathrm{Wu}, \mathrm{Wu}$, \& Feng, 2019). It is competitor oriented, however, enhanced value co-creation activities can help individual companies improve sales performance and support clustered sustainability, including through repeat tourism (Crick, Crick, \& Tebbett, 2020).

Every link of the value chain should create value for the customers in the next link. The TVC includes reception services, agricultural production, social governance, cultural displays, ecological experience, and space construction. This value-added link uses resource conversion as a main tool for transitioning to a combination of agricultural production and modern services, social culture, and intelligent technology (Lv, Zhang, \& Li, 2018). The important link of rural TVC is the mutual transformation of modern knowledge and local knowledge. However, the link also serves as a motivator to realize the value added to the full agricultural chain and to continuously advance the development of rural areas. The link of the value chain creates the primary sources of value with respect to production and sales networks for small-scale farmers wishing to connect with the international market. The modern agricultural value chain in rural areas has become a powerful tool for transforming the small-scale peasant economy. Emerging technologies are increasingly used and are potential drivers in sustainable agricultural supply chains, which include Internet of things, Blockchain, and Big data technology. These technologies are advancing the development of the agricultural supply chain into a data-driven digital supply chain environment (Kamble, Gunasekaran, \& Gawankar, 2020). However, if the rural tourism destination itself cannot create rich experiences that have value for tourists, it is harder to generate strong market demand. In that case, tourism practitioners may gradually withdraw from the field and reallocate resources (Hjalager, Tervo-Kankare, \& Tuohino, 2016).

Rural tourism destination is an important spatial basis to expand the TVC. The rural TVC is a powerful tool to identify strategic actions to ensure competitive advantages of the rural tourism destination. Rural tourism creates various types of values only through the coordination between the supply side and demand side. Production on the supply side is an integral part of the value creation process. It is the interaction of tourism participants that forms a value-added oriented agricultural organization mode and that realizes brand marketing. The key to the value chain is the "chain link value" in the production chain (Tejada, Santos, \& Guzmán, 2011). In rural area, farmer, organizations, and companies 
associated with the tourism are links in the TVC, providing experiential value for tourists and creating corresponding rewards and profits for themselves. Different links create different value based on the marketing ability and agricultural organization form of different participants. In particular, the value added from the tourist experience significantly influences the expansion and branding of the TVC.

With increasing differences in profit-making methods and actual profits, the relationship between different stakeholders has become increasingly close. However, there have also been increases in conflicts of interest, such as the contradiction between tourism development and the protection of traditional culture, directly affecting the sustainable development of tourism destinations (Song, Liu, \& Chen, 2013). It is difficult to describe all the participants in the value chain. However, the tourism organization includes stakeholders, suppliers, and agents, who together establish the value acquisition methods (Roxas, Rivera, \& Gutierrez, 2020). The value chain construction of China's rural tourism destinations somewhat lags other developed countries. For example, the coordinating relationships between the tourism organizational structure and the destinations need to be adjusted; the relationships between the local tourism enterprises that are linked with each other and with related enterprises needs to be further strengthened, and the mechanisms that link and distribute benefits in the TVC needs further improvement (Kim \& Thapa, 2018; Stienmetz, Kim, Xiang, \& Fesenmaier, 2020). In contrast with the construction of agricultural value chains, the construction of a TVC needs to allocate production and marketing along both vertical and horizontal directions. This requires the integration of elements that add value in the rural space. Together, these form the agricultural value chain, living value chain, social and cultural value chain, landscape value chain, and tourism reception service based on the local culture value chains (Weiermair, 2006).

The process of constructing a rural TVC has been characterized by construction through different stages, evolving from traditional sources of local value to the innovative value available in the new era. In the era of creative tourism, developing Internet based smart tourism integrates different cultural and creative elements to transform value elements, enriching the diversified experience value for tourists. Innovations based on local farmers' knowledge enhance the agricultural convergence of rural tourism, which changes the TVC from one of linear innovation to networking innovation. In constructing a TVC, main dimensions often include cultural protection, poverty alleviation, benefit sharing and space justice. The goal is to integrate endogenous and exogenous forces, and combine and optimize agricultural production, agricultural culture, indigenous culture, local ecology, rural education, spatial production, and other value elements (Li, 2017).

Stakeholders engaged in rural tourism can enhance the growth potential of local enterprises through network embeddedness, especially in small enterprises with family members as the core (Greenberg, Farja, \& Gimmon, 2018). The con- 
struction of TVC innovates existing paradigms associated with rural areas. It advances the transformation from productivism, which is the main production of agricultural products, to post-productivism of those products and associated services. With the implementation of China's new round of rural construction action and the development of new farmers' returning home and entrepreneurship based on post Productivism, all kinds of innovative values have emerged, such as the emergence of health care and research travel value (Xie, 2020). By integrating rural culture, nostalgia, and other emotional values, and by establishing long-term activities such as the "one village, one brand" and the "tourism trunk project," which means tourists drive to a certain destination by themselves, and after sightseeing, they use the trunk of their car to fill up with local products. Rural tourism plays an increasingly important role in the production of local products and restoring landscape spaces. This further integrates ecological, social, cultural and other non-productive factors, and improves tourism, leisure, and the well-being and level of the value of rural development.

Constructing a TVC establishes an effective governance mechanism, which represents the co-molding of brands, sharing channels, and realizing the integration of brand and channel. Promoting coordination, collaboration, and cooperation among different actors can promote consensus and learning in destination planning and management. This helps realize the value-based goals of different stakeholders in rural tourism destinations, and also help to improve the level of rural construction. It also enriches the types of ecological experience spaces that are available as tourism destinations, promoting high-quality constructing of TVC. The essence of a high-quality TVC is a value-added process that many stakeholders participate in, conducting business capture activities, pre-delivery support, delivery, and post-delivery support (Yilmaz \& Bititci, 2006).

Participants in rural tourism occupy different positions in the upper, middle, and lower reaches of the value chain, resulting in different value for each. In the personalized of rural destinations, it is important to coordinate the promotion of a Rural Revitalization Strategy and new urbanization strategy. Implementing a strategy that upgrades rural tourism products and establishing a value chain oriented performance management framework help stakeholders communicate and coordinate their tourism services and experiential activities in a more mature way, realizing the comprehensive value of rural tourism (Buffa, Beritelli, \& Martini, 2019).

Comprehensive value is created by the value network, which is composed of different value chains. Integrating the endogenous and exogenous power of value network, using information technology to promote the effective cooperation between the value modules of different business enterprises, improves the efficiency of those enterprises (Wang \& Kang, 2016). Rural tourism organically integrates life activities, food cooking, handicrafts manufacturing and landscape constructing, and enhances the brand value of rural space. Rural tourism establishes the network connection between local supply factors and the target mar- 
ket, enriches the meaning associated with TVC, increases the income of indigenous people from multiple factors, and promotes the development of multifunctional agriculture in China (Zheng \& Liu, 2014).

Rural tourism is an important driving force for the development of multifunctional agriculture, constructing a TVC follows similar paths as the development of multifunctional agriculture (Hrabák \& Konečný, 2018). First, it mirrors the horizontal path of the leisure agriculture with respect to the multifunctionality of agriculture. Second, it is consistent with the vertical path of close vertical cooperation. Third, it aligns with the leisure agriculture with complete types path, which has typical vertical and horizontal characteristics (Martínez-Pérez, Elche, \& García-Villaverde, 2019; Weiermair, 2006). To expand the value chain of rural tourism, we should further extend the multifunctional agricultural value chain vertically and horizontally, take relevant measures to enrich the meaning associated with each link in the value chain, and introduce new technologies, new formats, and new models into the rural tourism. The constructing goal of the TVC should be to realize agricultural integration, functional expansion and value promotion, and improve the production efficiency and income of modern agriculture (Han, 2018; van der Zee, Gerrets, \& Vanneste, 2017).

These interactive links are composed of activities that provide both basic and auxiliary value, which promote TVC development. Internally consistent elements combine to create a scenario of rural tourism activities. Rural tourism activities should reflect the background attribute of rural social value and the basic attribute of the service industry. The combination of endogenous and exogenous forces should advance scientific innovation, technological progress, and institutional innovation. At the same time, it is necessary to absorb the value created by tourists participating in experiential activities to realize the effective management of value chain co-creation (Wan, 2019). This kind of value chain co-creation can reflect the supply of rural tourism destination value elements and the ability to respond to market demand. It can also create new rural development paradigm, integrate agricultural and rural scenery, and enhance the sharing experience between urban and rural areas. At the same time, the TVC provides value-added information for different decision makers, enterprises and tourists. In particular, these value activities enrich rural residents' livelihoods that upgrade beautiful rural construction.

As TVC has been expanded to many fields, its service and rural value chains have also faced such problems as product homogeneity, short industrial chains, low integration ability, single modes, and low-end products (Zhang \& Kong, 2020). The outbreak and spread of the covid-19 epidemic led to the economic interruption of the global tourism supply chain, resulting in a substantial reduction in the income of tourism operators. This created a sustainable development problem for all stakeholders (González-Torres, Rodríguez-Sánchez, \& Pelechano-Barahona, 2021). For example, in developing countries, the vertical organization of tourism is an obstacle to integrating rural stakeholders into tourism de- 
velopment. Tourism organizations composed of different departments control the core area, and determine the profit for the marginal areas participating in tourism development (Adiyia et al., 2015). This study explores how to balance the interests of core areas and marginal areas, empower local farmers, and put their interests in the development of rural tourism in a more important position, and build a high-quality rural tourism system. The goal was to keep the interests of the core and marginal areas consistent, which was designed to increase the proportion of the indigenous value with respect to the development of rural tourism.

This study applied the cross-impact balance analysis (CIB) to select the best scenario, which combined many value elements associate with the goal of constructing a high-quality TVC. The CIB has the advantages of improving the traceability and reproducibility of the construction of each scenario, better consistency of scenarios and integrity of the theme (Vögele, Rübbelke, Govorukha, \& Grajewski, 2020). By judging the interaction of the main elements in the rural TVC, a reasonable and consistent scenario about the behavior of the TVC is constructed. The consistent scenario of the TVC is very similar to a qualitative system, and CIB has been used widely to conduct qualitative system analyses in the fields of energy, climate, education, health, society, and others (Vögele et al., 2020; Weimer-Jehle, 2006). This qualitative method is mainly to use the feedback from relevant experts to calculate the "consistent scenario of various scenarios" of the rural TVC.

\section{Theoretical Framework of Rural Tourism Value Chain}

Tourism products and services provided in rural tourism destinations represent economic and social activities, which constitute a decentralized value chain of elements. The result is different links and interactions in regional economic structures (Romão, 2020). In the theoretical framework, the TVC includes vertical and horizontal chains of the rural tourism (Figure 1). These chains cross each other, and establish the value chain that includes both basic and auxiliary value activities. The construction of the TVC includes five value chains: life, industry, society, ecology, and culture. These chains include the value elements of rural scenery, folk customs, biological diversity, traditional culture, and participatory activities. The basic value activities of rural tourism mainly include tourism service products based on local characteristic resources, such as catering, accommodation and entertainment. The auxiliary value activities of rural tourism mainly include the construction of tourism infrastructure and the protection of social and cultural environment. Together, these form several value chain combinations (or Scenarios) Scenarios in a way of cross evaluation. This study focused on selecting the scenario that makes it most suitable for each value element to participate in constructing the TVC. The study considers how elements with less value could be combined to expand the TVC of the tourism destination. 


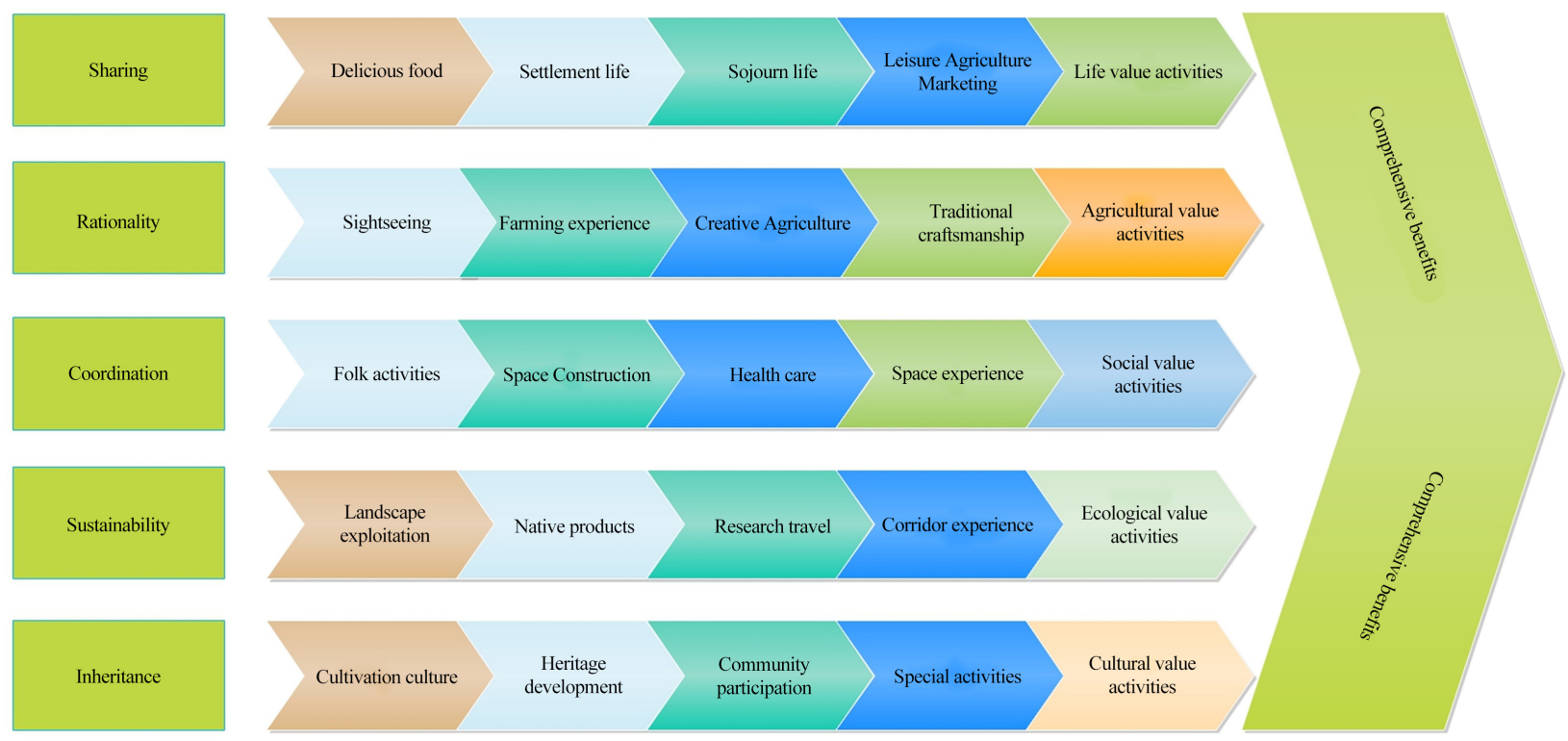

Figure 1. The basic structure of rural TVC theoretical framework.

\section{Research Method}

\subsection{Study Area}

Dalishu village is located in the southwest of Fengcheng City, Liaoning Province, China. It has a convenient transportation network that includes both highway and railway and is easily reached from all directions. The climate is mild with abundant rainfall and vegetation, and there are four distinct seasons. The winter isn't overly cold and the summer isn't overly hot, making it suitable for human settlement. The village governs 22 village groups, with a total population of 4800 people and a total area of $4800 \mathrm{hm}^{2}$. The cultivated land area is $495 \mathrm{hm}^{2}$, and the forest area covers $3596 \mathrm{hm}^{2}$.

Since the implementation of the Household Responsibility System in 1978, Dalishu village has experienced four stages of value chain construction: traditional agriculture, the combination of agriculture and industry, rural tourism, and multifunctional agriculture. As important driving forces, value-added elements such as characteristic agriculture, new business forms, spatial transformation and regional cultural integration are constantly entering the local value chain. The production of agricultural products continues to extend to circulation, processing, tourism, and other links, and there have been continuous improvements in supporting elements such as land, capital, technology, and organization. This has created new value, with a substantial increase of local income and core new social values. After more than 30 years of development, a number of value chains have formed, including an agricultural value chain with modern multifunctionality as the core (Zheng \& Ma, 2015), TVC with eco-tourism as the core, a cultural value chain with the spirit of "active efforts" as the core, and a landscape value chain with leisure experience as the core (Zheng, Wang, Luo, \& Zhou, 2019). The following table (Table 1) lists the driving forces, transformation forms and core values of the four development stages of Dalishu village. 
Table 1. TVC construction process in Dalishu village.

\begin{tabular}{|c|c|c|c|c|}
\hline $\begin{array}{l}\text { Construction } \\
\text { process }\end{array}$ & $\begin{array}{l}\text { Stage I } \\
(1980 s)\end{array}$ & $\begin{array}{l}\text { Stage II } \\
(1990 s)\end{array}$ & $\begin{array}{l}\text { Stage III } \\
(2000-2005)\end{array}$ & $\begin{array}{l}\text { Stage IV } \\
(2006-2020)\end{array}$ \\
\hline Driving force & $\begin{array}{l}\text { Driven by production } \\
\text { enthusiasm of farmers to the } \\
\text { Household Responsibility } \\
\text { System: the agricultural } \\
\text { production has enhanced the } \\
\text { vitality of rural development. }\end{array}$ & $\begin{array}{l}\text { Driven by the integration of } \\
\text { agriculture and other } \\
\text { industries: township } \\
\text { enterprises have achieved the } \\
\text { benefits of from agricultural } \\
\text { production to other industries. }\end{array}$ & $\begin{array}{l}\text { Adjustment of planting } \\
\text { structure driven by the } \\
\text { ecological construction of the } \\
\text { village space and the } \\
\text { development of leisure } \\
\text { agriculture. }\end{array}$ & $\begin{array}{l}\text { Rural tourism driven by the } \\
\text { development of } \\
\text { multifunctional agriculture and } \\
\text { the construction of } \\
\text { multifunctional landscape } \\
\text { network. }\end{array}$ \\
\hline $\begin{array}{l}\text { Transformation } \\
\text { form }\end{array}$ & $\begin{array}{l}\text { The positive transformation } \\
\text { of agricultural production } \\
\text { promoted the diversification } \\
\text { of agricultural products. }\end{array}$ & $\begin{array}{l}\text { Industrial and commercial } \\
\text { integration: the development } \\
\text { of the processing industry and } \\
\text { commerce changed the } \\
\text { industrial structure. }\end{array}$ & $\begin{array}{l}\text { Industrial Integration: } \\
\text { promoted the coordinated } \\
\text { development of } \\
\text { multifunctional agriculture } \\
\text { and multi-functional } \\
\text { landscape network. }\end{array}$ & $\begin{array}{l}\text { New agriculture: the } \\
\text { construction of the modern } \\
\text { agricultural value chain } \\
\text { promoted the construction of } \\
\text { new industry and a beautiful } \\
\text { countryside. }\end{array}$ \\
\hline Core values & $\begin{array}{l}\text { Agricultural value: Farmers' } \\
\text { enthusiasm for production } \\
\text { was enhanced and the } \\
\text { agricultural value chain } \\
\text { expanded. }\end{array}$ & $\begin{array}{l}\text { Industrial and commercial } \\
\text { value: the integration of } \\
\text { industry and commerce into } \\
\text { the agricultural field expanded } \\
\text { the agricultural value chain. }\end{array}$ & $\begin{array}{l}\text { Leisure Value: the } \\
\text { development of sightseeing } \\
\text { agriculture enhanced the } \\
\text { leisure-based experiential } \\
\text { value of traditional } \\
\text { agriculture. }\end{array}$ & $\begin{array}{l}\text { Shared value: agricultural } \\
\text { innovation and spatial } \\
\text { integration expanded the } \\
\text { shared value of multifunctional } \\
\text { agriculture. }\end{array}$ \\
\hline
\end{tabular}

Source: Field survey by authors, 2016-2020

Together, these have developed and extended the township and rural agriculture into high-end fields, with high technology levels and added value. This development has also enhanced the comprehensive competitiveness of rural agriculture and has improved the level of transformation and upgrades to rural agriculture. Dalishu village has created a shared experience space with different types, functions, and interactions, and has enhanced the comprehensive value of the village. The village has received the titles of "national AAAA scenic spot," "national agricultural tourism demonstration site," and the status of being a "China Agricultural Park." Its "go all out" spirit with regional characteristics has become an important model for the construction of other beautiful villages in China (Zheng, Li, Guo, \& Wang, 2020). Rural tourism has led to great changes with respect to structural adjustment, organization and implementation, and chain performance. However, there are still some problems in the rural TVC. These problems include a low level of comprehensive development, the insufficient extension of the industrial chain, and unequal income sharing among farmers. These problems are also general problems

As can be seen from Table 1, the rural TVC construction in Dalishu village has the following four stage characteristics:

1) The first stage of the TVC construction involved the combination of agriculture, industry, and commerce. The driving force of this stage is mainly from the transfer of the production enthusiasm of farmers to the Household Responsibility System. Since the implementation of the Household Responsibility System in the 1980s, Dalishu village has explored the development mode of combining agriculture with industry and commerce, creating the "first pot of gold" 
in the transform development. Knowledge from both inside and outside the region has injected innovative vitality into the development of rural tourism. In other words, based on the traditional agriculture, the development of township enterprises mainly engaged in the processing of industrial products, and the establishment of agricultural trade markets. This laid the foundation for constructing a value chain that integrated agriculture, industry, and commerce, with ecological agriculture as the core.

2) The next stage of value chain construction was ecological agriculture. The driving force of this development stage mainly comes from the integration of agriculture and other industries. Dalishu village, which has achieved the benefits of from agricultural production to other industries, had professionalized traditional agriculture concepts, and began to change the industrial structure and spatial layout. Dalishu village transformed a thousand ha barren mountain into a "flower and fruit mountain" for planting fruits. The large area of fruit planting changed the structure of planting grain only. Traditional Chinese medicine planting took the lead in planting traditional Chinese medicinal plants, mainly Schisandra chinensis, in Eastern Liaoning. This adjusted the planting structure of traditional agriculture, and led to a large-scale adjustment of the planting structure in surrounding areas. These adjustments created a new type of ecological landscape and accumulated a rich spiritual meaning where every effort was devoted to action (Gan).

3) The construction of the leisure agriculture value chain was the third stage. The driving force of this development stage mainly comes from the ecological construction of agriculture and the development of leisure agriculture. Ecological construction changed traditional agricultural structure, and increased the pressure of market competition. The changes created by industrial foundation, ecological engineering and landscape construction also brought about sightseeing agriculture. Tourism products, including scenic spots, transportation, bed and breakfasts (B \& Bs), restaurants, and specialty shops became a model for tourism exhibition in Eastern Liaoning. Projects such as the "Huaguo Mountain" (Mountain of Flowers and Fruits), "Yaowanggu" (the "King of Remedies"), "Film and television city" (a film and television shooting base), and the reconstruction of new residential villages advanced the local overall image and created a regional brand of sightseeing agriculture. The opportunities associated with the tourism market were fully occupied, laying a market foundation for the subsequent development of leisure agriculture, rural tourism, and multifunctional agriculture.

4) The most recent stage of development has been the construction of a multifunctional agricultural value chain. The driving force of this development stage mainly comes from the development of multi-functional agriculture and the construction of multi-functional landscape network. As a new social and economic network, rural tourism development has been embedded in the multifunctional agricultural innovation network, advancing the integration and in- 
novation of primary, secondary, and tertiary industries. This has created a new rural landscape space and represents various types of landscapes. The "colorful garden" agricultural park constructed by the Internet, Internet of things, and automatic control has enriched crop varieties and the meaning associated with leisure-based experiential activities. It has changed the strong seasonal trend of rural tourism and provides tourism services directly or indirectly to foreign tourists through travel agencies. This has formed a unique distribution channel and has promoted the construction of the TVC. At the same time, rural tourism with culture as a core component, have injected new vitality into the integration of culture and tourism. Sports events, farmers' harvest festivals, the peach blossom festival, and other activities have further innovated the meaning associated with rural tourism activities, and have realized the high-quality development of multifunctional agriculture.

\subsection{Analysis Process}

\section{Verification Method of Theoretical Framework of the Rural TVC}

According to the theoretical framework, the value chain of rural tourism is a target scenario composed of many value elements, and has complex network characteristics. These elements of value interact with each other to establish a variety of complex scenarios. As a data analysis technique, CIB was used to verify the theoretical framework associated with the construction of the rural TVC. The reason why we use this method to explore the construction of rural tourism value chain is that the realization direction of rural tourism value elements is consistent with the implementation goal of Rural Revitalization Strategy. When considering the coexistence of target scenarios composed of multiple value elements, this study applied CIB to synthesize generally isolated information involved in constructing the rural TVC. In other words, the method integrates the vertical and horizontal related elements of TVC, so selecting a scenario can be based on various value elements. The dynamic changes of these value elements are determined by different combinations in the theoretical framework. The basic steps applied were as follows:

1) Selection of value elements of the rural TVC. Field investigations and in-depth interviews were used to elicit indigenous peoples' views on the selection of different elements, such as rural landscape, settlement space, agricultural production, and folk customs. Through on-the-spot investigation and training of local tourism operators, we have maintained continuous communication with local people for several years, and each in-depth interview with local people takes 2 - 3 hours. The in-depth interviews were supported by the observation results of participants and non-participants. In the interviews with them, the topics of conversation focused on the current situation, characteristic products, profit points and main problems of rural tourism development in Dalishu village. Combined with the tourism strategies used by Chinese professional websites such as Mafengwo and ctrip.com, data about agricultural development, community participation, characteristic landscape, ecological environment and social environment 
were collected. Based on the explicit knowledge and tacit knowledge provided by local people, 20 elements across five value chains were used to select the scenarios. The best scenarios should be a simple combination of leading value elements and make it a scenario to guide the coordinated development of other value elements.

2) Construct the cross-impact matrix of the rural TVC. The matrix contains the cross-impact elements of the TVC, which represent different scenarios of rural areas seeking high-quality development. With the development of digital technology (such as Big data, virtual reality technology, cloud computing, artificial intelligence and blockchain), the way in which rural tourism enterprises gain value-added has changed a lot, which promotes the formation of more innovative values. These value elements reflect specific coupling relationships with the five goals of the Rural Revitalization Strategy, which is important for guiding the high-quality development of rural tourism. Scenarios were constructed around the five value chains of life, industry, ecology, society, and culture. The value elements of rural TVC mainly included: delicious food, village experience, tourism life, agricultural tourism marketing; sightseeing, farming experience and specialized skills; folk activities, space experience, living and health care, and space sharing; landscape development, specialty experience, research travel, and green landscape corridor. There were 20 value elements, including farming culture, heritage experience, community participation, and thematic activities of rural tourism.

3) Generate cross-impact matrix of the rural TVC. According to the value elements listed in the theoretical framework of the rural TVC (Figure 1), the cross-impact matrix including the interaction of value elements is established. Figure 2 shows that local research and our judgments are used to generate influential value elements in the cross-impact matrix. The state in the row is the source of the impact, and the state of the column is the target of the impact. Each matrix is distributed according to the mutual influence of value elements, and the sum of its rows is zero. The scores were as follows: -3 indicated a strongly restricting influence; -2 indicated a moderately restricting influence; -1 indicated a weakly restricting influence; 0 indicated no influence; +1 indicated a weakly promoting influence, +2 indicated a moderately promoting influence; and +3 indicated a strongly promoting influence. The row descriptor of the judgment part represents the source of the influence, and the column descriptor represents the target of the impact. Scenario wizard software, designed by Wolfgang Weimer-Jehle to apply CIB was used to analyze the qualitative relationship of the network behavior through structured "cross-impact data" (Weimer-jehle, 2014).

\section{Research Results}

1) Elements of the preferred scenario. The scenario generated from the combinations in the Scenario Wizard software provided an analysis of the combined value elements for each hypothetical scenario, reporting the advantages and disadvantages of each scenario. In all the possible scenarios, the best scenario 


\begin{tabular}{|c|c|c|c|c|c|c|c|c|c|c|c|c|c|c|c|c|c|c|c|c|}
\hline & & A & & & & $\mathrm{E}$ & & & & $\mathrm{C}$ & & & & & & & & & & \\
\hline & A1 & A2 & $\mathrm{A} 3 \mathrm{~A}$ & & B1 & B2 & & B4 & C1 & & $\mathrm{C} 3$ & C4 & D1 & & D3 & D4 & E1 & & E3 & E4 \\
\hline A. Ecological value activities & & & & & & & & & & & & & & & & & & & & \\
\hline -A1 Delicious food & & & & & 3 & 3 & -3 & -3 & 3 & -3 & -1 & 1 & 3 & -1 & $\mid-1$ & -1 & 3 & -3 & 1 & $\mid-1$ \\
\hline -A2 Settlement life & & & & & 2 & 3 & -2 & -3 & 2 & -3 & 3 & -2 & 3 & -2 & 2 & -3 & 3 & -3 & 3 & -3 \\
\hline -A3 Sojourn life & & & & & 3 & 3 & -3 & -3 & 2 & -2 & 2 & -2 & 2 & 1 & -2 & -1 & 3 & -3 & 3 & -3 \\
\hline -A4 Leisure Agriculture Marketing & & & & & -1 & 1 & 2 & -2 & 2 & -3 & 0 & 1 & -2 & -2 & 2 & 2 & 1 & 1 & -1 & -1 \\
\hline B. Agricultural value activities & & & & & & & & & & & & & & & & & & & & \\
\hline -B1 Sightseeing & -1 & $|-3|$ & 3 & 1 & & & & & 2 & -2 & 2 & -2 & 1 & -3 & 1 & 1 & 3 & -1 & -1 & -1 \\
\hline -B2 Farming experience & -3 & 1 & 1 & 1 & & & & & -1 & 2 & -1 & 0 & 2 & -2 & 0 & 0 & 3 & -1 & -1 & -1 \\
\hline -B3 Creative Agriculture & -1 & 1 . & -1 & 1 & & & & & 2 & 0 & -2 & 0 & 3 & -2 & -1 & 0 & 1 & -1 & -1 & 1 \\
\hline -B4 Traditional craftsmanship & -1 & -2 & 1 & 2 & & & & & -3 & 1 & 1 & 1 & 1 & 1 & 1 & -3 & -1 & -1 & 1 & 1 \\
\hline C. Social value activities & & & & & & & & & & & & & & & & & & & & \\
\hline -C1 Folk activities & 1 & 2 & 0 & -3 & 1 & 2 & 0 & -3 & & & & & 3 & -2 & -1 & 0 & 3 & -3 & 2 & -2 \\
\hline -C2 Space Construction & 2 & 2 & -2 & -2 & -2 & 2 & 2 & -2 & & & & & 3 & -2 & -1 & 0 & -2 & -1 & 3 & 0 \\
\hline -C3 Health care & 1 & 3 & -1. & -3 & \begin{tabular}{|c|} 
\\
-1 \\
\end{tabular} & 2 & -2 & 1 & & & & & 3 & -2 & -1 & 0 & \begin{tabular}{|l|}
1 \\
\end{tabular} & -2 & 1 & 0 \\
\hline -C4 Space experience & 0 & 2 & -3 & 1 & -1 & 1 & 2 & -2 & & & & & -2 & -1 & 1 & 2 & -1 & 0 & 1 & 0 \\
\hline D. Ecological value activities & & & & & & & & & & & & & & & & & & & & \\
\hline -D1 Landscape exploitation & 2 & 3 & $\mid-2$ & -3 & -3 & 2 & 1 & 0 & 2 & -1 & -1 & 0 & & & & & 2 & 1 & -2 & -1 \\
\hline -D2 Native products & 1 & 3 & -2 & -2 & -2 & 2 & 0 & 0 & -3 & 2 & 2 & -1 & & & & & 3 & -1 & -1 & -1 \\
\hline -D3 Research travel & -1 & 3 & $1-$ & -3 & -3 & 2 & 1 & 0 & 1 & -1 & -1 & 1 & & & & & 1 & -3 & 1 & 1 \\
\hline -D4 Corridor experience & -1 & 3 & -1. & -1 & \begin{tabular}{|l|}
1 \\
\end{tabular} & 1 & 1 & -3 & 2 & -2 & -1 & 1 & & & & & 2 & -2 & -1 & 1 \\
\hline E. Cultural value activities & & & & & & & & & & & & & & & & & & & & \\
\hline -E1 Cultivation culture & 1 & 3 & $\mid-1$ & -3 & 3 & 3 & -3 & -3 & 2 & 2 & -2 & -2 & 3 & -2 & 2 & -3 & & & & \\
\hline -E2 Heritage development & 2 & 2 & -3 & -1 & 2 & -3 & 1 & 0 & \begin{tabular}{|l|l|}
-2 \\
\end{tabular} & -1 & 2 & 1 & -2 & -3 & 3 & 2 & & & & \\
\hline -E3 Community participation & 1 & 3. & -3 & -1 & 2 & -1 & -1 & 0 & -2 & 2 & -1 & 1 & -1 & -1 & 1 & 1 & & & & \\
\hline -E4 Special activities & \begin{tabular}{|l|l|}
-1 \\
\end{tabular} & 3 & $-3 \mid$ & 1 & \begin{tabular}{|l|l|}
-1 \\
\end{tabular} & 1 & 1 & -1 & \begin{tabular}{|l|}
1 \\
\end{tabular} & 1 & -1 & -1 & -1 & -1 & 1 & 1 & & & & \\
\hline & & v & & & & v & & & $\mathrm{v}$ & & & & $\mathrm{v}$ & & & & $\mathrm{v}$ & & & \\
\hline Balance: & 1 & \begin{tabular}{|l|l|l}
9 & \\
\end{tabular} & \begin{tabular}{|l|l}
-2 & - \\
\end{tabular} & -8 & 3 & 10 & -4 & -9 & 5 & 0 & -1 & -4 & 11 & -8 & 3 & -6 & 11 & -6 & 2 & -7 \\
\hline
\end{tabular}

Figure 2. The choice of scenario of rural TVC (Source: Scenario Wizard 4.3).

combination scenario was reported as: "farming experience + village experience + folk activities + landscape development + farming culture". More than 100 combinations were possible from the 20 scenario value elements. The combination of internal value elements was determined to support each other when the consistency values of the combination reached the optimal state. From the perspective of life value activities, delicious food, settlement life, the sojourning life, and new marketing are all good choices. However, the problem is whether they can be combined with other elements to form a perfect scenario. This is because some elements cannot achieve a positive role in advancing other value elements in the scenario. From the perspective of agricultural value activities, sightseeing activities, farming experience, and creative agriculture, traditional craftsmanship can be selected to support the scenario of the TVC. However, combinations of these and other elements may be inconsistent, meaning it is not appropriate to combine them into an optimized scenario suitable for indigenous tourism development. Many value elements appear to be good choices on the surface but are difficult to achieve when combined with other indigenous elements. The combination of elements in this scenario had high levels of consistency, which was consistent with rural tourism development goals and Rural Revitalization Strategy. For example, the village's experiential activities were most strongly affected by landscape development, farming experience, folk activities and farming culture elements (as shown in Figure 3).

2) The reliability of the combination scenario. A comprehensive analysis of the consistency, reliability of scenario assumptions, path analysis, and system grid shows that scenario elements effectively control other elements. Scenario assumptions had three types of consistency: strong consistency, weak consistency, and maximum inconsistency. The content of the scenario assumptions with 
strong consistency (Table 2) is acceptable. The path analysis mainly describes the indirect influence between the two elements; it helps explain the scenario's effect. In general, the CIB's "consistent scenario" automatically considers all the indirect influences of the first or higher order. The reliability of assumptions in each scenario is also expressed by the "consistency value," which is the difference between the impact score and the best alternative hypothesis score. The list in Table 2 provides the reliability of value elements in descending order. The content of scenario with the highest internal consistency is listed first.

The network analysis results of the preferred scenarios show that the active and passive sum of different value elements indicates their activity and passivity (Figure 4). In the system grid formed by the passive sum as the $\mathrm{X}$ coordinate and the active sum as the $\mathrm{Y}$ coordinate, the value elements in the preferred scenario are all located in the upper right corner. This indicates that these value elements have higher active and passive sums, which can effectively influence other value elements in the construction of the TVC, and providing a linkage effect.

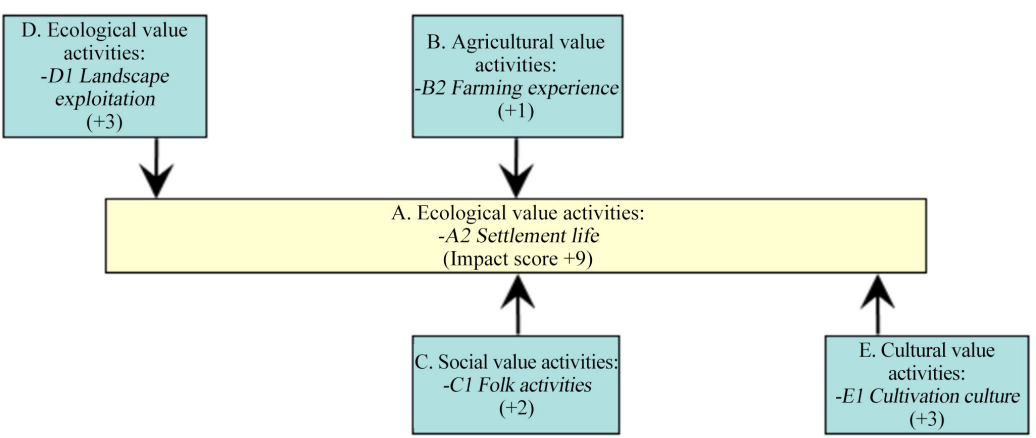

Figure 3. Impact diagram of value elements in scenario (Source: the running results of ScenarioWizard 4.3).

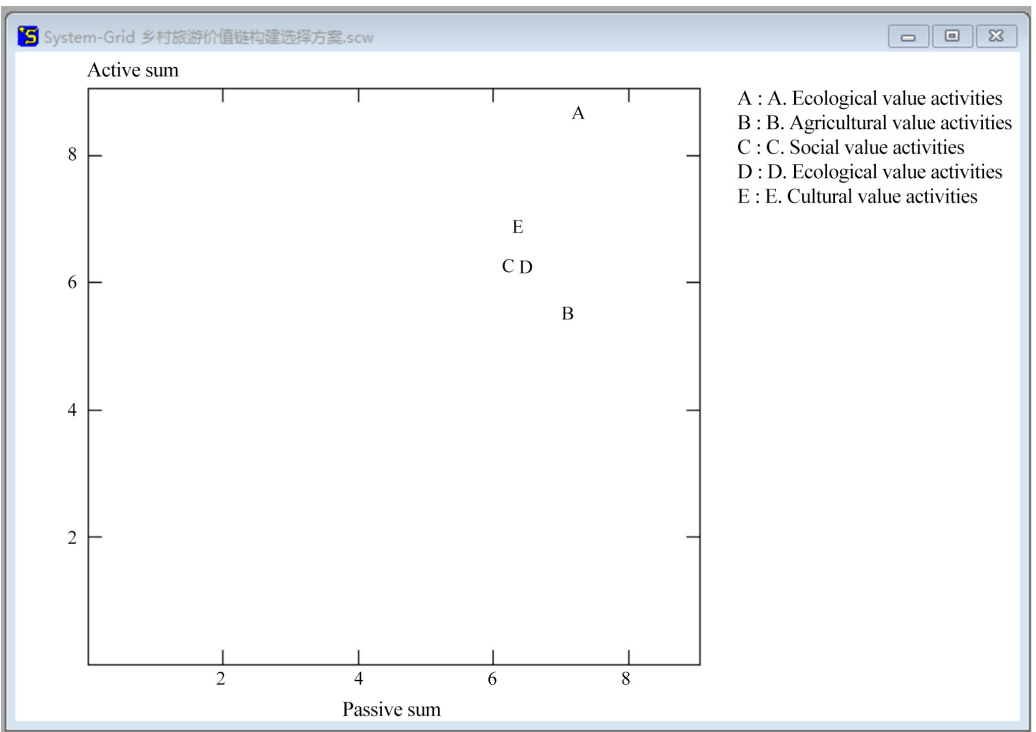

Figure 4. Grid of rural tourism values chain (Source: running results of ScenarioWizard 4.3). 
Table 2. Firmness of scenario assumptions.

\begin{tabular}{lll}
\hline Value activities & Value elements & Consistency Value \\
\hline E. Cultural value activities & -E1 cultivation culture & 9 \\
A. Life value activities & -A2 Settlement life & 8 \\
D. Ecological value activities & -D1 Landscape exploiting & 8 \\
B. Production value activities & -B2 Farming experience & 7 \\
C. Social value activities & -C1 Folk activities & 5 \\
\hline
\end{tabular}

(Source: running results of Scenario Wizard 4.3).

\section{Conclusion}

1) The construction of a TVC is a network embedding process that evolves from a low to high level of value formation, which can transform the necessary knowledge of all kinds of tourism operators in innovation activities and produce new values that are conducive to the construction of value chain. The rural TVC includes knowledge and technology, traditional culture, natural ecology, agricultural landscape, all kinds of species and other comprehensive categories, as well as rich and diverse resources and elements that can be transformed. The innovation of rural tourism value chain is inseparable from the optimization and upgrading of industrial structure. The construction of the value chain relates both to the vertical hospitality industry and the horizontal rural space ecological environment, social status, life goals, and cultural forms. The value elements with a strong leading role integrate scattered value elements into the TVC. For example, delicious food impacts agricultural culture and produces other value in rural society. A value chain with strong leading factors is embedded in the process of rural tourism network, which advances the mutual transformation of tacit and explicit knowledge and forms innovative knowledge. It is necessary to take the top-down design and bottom-up practice to explore the innovative construction path of the rural TVC. This innovation process overcomes the marketing barriers in the embedding process, and transforms innovation from a traditional linear form to a modern network form. It is necessary to actively manage the stakeholder interaction and power relationship in rural tourism, so as to expand the tourism industry into regional development. Moreover, it is necessary to maintain the vitality of the TVC, which will help to improve the poverty alleviation ability of rural tourism. Leading enterprises play a role by embedding activity such as "one village, one brand" and "tourism trunk project". This constructs an agricultural value chain based on the value network, and advances the high-quality construction of a rural multifunctional agricultural innovation network. The embedding process of value elements in an optimized scenario allows the elements to cooperate with each other with a high level of internal consistency. Use information technology, Internet of things and Cloud computing modern technology to promote the dissemination of information and knowledge about value elements among stakeholders, so as to improve the competitiveness 
of innovation and destination.

2) The construction of a TVC is a non-linear process, where the leading role of each value element is unbalanced. The non-linear process of value construction integrates the productive value with non-productive value, consumption value, ecological value and cultural value. The unbalanced distribution of these value elements in industry, society, culture, ecology and other fields is mainly reflected in the different space of value realization. As a kind of space to realize experience value, ecological experience field is an important direction of TVC construction. Relying on the experience space, with distinctive characteristics and rich types, the preferred value elements can maximize their leading role in the construction of TVC. This can transform scattered value elements into an important thrust force for developing rural tourism through linear and network methods. Focusing on the selected value elements, a rural tourism consortium that combines online and offline resources exogenous "top-down" government led activities and endogenous "bottom-up" community participation to break through the obstacles of TVC expansion and improve value chain relationship governance. By transforming value elements, such as land circulation and innovation platform building, a new relationship with rural residents' production, life, society and culture is established. This advances the comprehensive integration of the primary industry, secondary industry, and tertiary industry, as well as high-quality TVC construction. This also promotes the collaborative innovation level of settlement space, folk customs, and the cultural landscape.

3) Constructing a TVC should address the transformative function of urban and rural value elements. These value elements that can play a leading role between urban and rural areas can be effectively combined to enhance their competitive advantage. It is necessary to invest capital into the value elements with high efficiency and play a leading role in the construction of TVC. At the same time, it is necessary to encourage the use of social capital to maximize new financing modes available with mode of Internet convergence and "Public-Private-Partnership" to increase the effective supply of value elements. From a vertical perspective, we should innovate the production mode enabled by the TVC, advance the mutual transformation between external value and "indigenous value". It is necessary to strengthen the construction of information infrastructure in key rural tourism areas, and achieve effective docking between local value chains and external value chains. Furthermore, it is necessary to establish the most appropriate TVC governance mode, and achieve strategic interaction with competitors. From a horizontal perspective, we should integrate rural historical and cultural elements, traditional skills, ecological environment, production experience, social culture and other elements, so that they can become the leading elements in the construction of TVC. We should promote the integration of agricultural elements and cultural creativity, and improve the emotional value and diversified consumption value of agricultural products. We should eliminate the low-end fixed position of value chain segmentation, and enhance 
the profitability of value elements in the value chain. We should guide regional cultural elements into TVC construction to enhance the market competitive position of rural tourism. The construction level of rural spatial value, such as traditional rural technology and special skills, is advanced by the concept of shared development. This supports the construction of the value chain of rural tourism with branding, human culture, and intelligence. This would ultimately improve the coupling level of rural tourism and Rural Revitalization.

\section{Acknowledgements}

This project was funded by the National Social Science Fund Project of China (15BGL118).

\section{Conflicts of Interest}

The authors declare no conflicts of interest regarding the publication of this paper.

\section{References}

Adiyia, B., Stoffelen, A., Jennes, B., Vanneste, D., \& Ahebwa, W. M. (2015). Analysing Governance in Tourism Value Chains to Reshape the Tourist Bubble in Developing Countries: The Case of Cultural Tourism in Uganda. Journal of Ecotourism, 14, 113-129. https://doi.org/10.1080/14724049.2015.1027211

Buffa, F., Beritelli, P., \& Martini, U. (2019). Project Networks and the Reputation Network in a Community Destination: Proof of the Missing Link. Journal of Destination Marketing \& Management, 11, 251-259. https://doi.org/10.1016/j.jdmm.2018.05.001

Crick, J. M., Crick, D., \& Tebbett, N. (2020). Competitor Orientation and Value Co-Creation in Sustaining Rural New Zealand Wine Producers. Journal of Rural Studies, 73, 122-134. https://doi.org/10.1016/j.jrurstud.2019.10.019

González-Torres, T., Rodríguez-Sánchez, J.-L., \& Pelechano-Barahona, E. (2021). Managing Relationships in the Tourism Supply Chain to Overcome Epidemic Outbreaks: The Case of COVID-19 and the Hospitality Industry in Spain. International Journal of Hospitality Management, 92, Article ID: 102733.

https://doi.org/10.1016/j.ijhm.2020.102733

Greenberg, Z., Farja, Y., \& Gimmon, E. (2018). Embeddedness and Growth of Small Businesses in Rural Regions. Journal of Rural Studies, 62, 174-182.

https://doi.org/10.1016/j.jrurstud.2018.07.016

Han, J. (2018). “Circle-Chain-Layer”: The Operation Mode of Agricultural Industry Chain and Its Value Integration Governance Innovation-Based on the Perspective of Agricultural Industry Integration. Economist, No. 10, 97-104.

Hjalager, A.-M., Tervo-Kankare, K., \& Tuohino, A. (2016). Tourism Value Chains Revisited and Applied to Rural Well-Being Tourism. Tourism Planning \& Development, 13, 379-395. https://doi.org/10.1080/21568316.2015.1133449

Hrabák, J., \& Konečný, O. (2018). Multifunctional Agriculture as an Integral Part of Rural Development: Spatial Concentration and Distribution in Czechia. Norsk Geografisk Tidsskrift-Norwegian Journal of Geography, 72, 257-272.

https://doi.org/10.1080/00291951.2018.1532967

Kamble, S. S., Gunasekaran, A., \& Gawankar, S. A. (2020). Achieving Sustainable Perfor- 
mance in a Data-Driven Agriculture Supply Chain: A Review for Research and Applications. International Journal of Production Economics, 219, 179-194.

https://doi.org/10.1016/j.ijpe.2019.05.022

Kim, M., \& Thapa, B. (2018). Perceived Value and Flow Experience: Application in a Nature-Based Tourism Context. Journal of Destination Marketing \& Management, 8, 373-384. https://doi.org/10.1016/j.jdmm.2017.08.002

Li, F. (2017). A New Inquiry on the Tourism Targeted Poverty Alleviation from the Perspective of Embedded Rural Value. Tourism and Hospitality Prospects, 1, 1-17+105.

Lv, W., Zhang, D., \& Li, L. (2018). A Research on the Connotation and Characteristics of Rural Tourism Industry Chain. Tourism Forum, 11, 30-37.

Martínez-Pérez, Á., Elche, D., \& García-Villaverde, P. M. (2019). From Diversity of Interorganizational Relationships to Radical Innovation in Tourism Destination: The Role of Knowledge Exploration. Journal of Destination Marketing \& Management, 11, 80-88. https://doi.org/10.1016/j.jdmm.2018.12.002

Porter, M. E. (1985). Competitive Advantage: Creating and Sustaining Superior Performance: With a New Introduction. Cambridge: Free Press.

Romão, J. (2020). Tourism, Smart Specialisation, Growth, and Resilience. Annals of Tourism Research, 84, Article ID: 102995. https://doi.org/10.1016/j.annals.2020.102995

Roxas, F. M. Y., Rivera, J. P. R., \& Gutierrez, E. L. M. (2020). Framework for Creating Sustainable Tourism Using Systems Thinking. Current Issues in Tourism, 23, 280-296. https://doi.org/10.1080/13683500.2018.1534805

Song, H., Liu, J., \& Chen, G. (2013). Tourism Value Chain Governance: Review and Prospects. Journal of Travel Research, 52, 15-28. https://doi.org/10.1177/0047287512457264

Stienmetz, J., Kim, J., Xiang, Z., \& Fesenmaier, D. R. (2020). Managing the Structure of Tourism Experiences: Foundations for Tourism Design. Journal of Destination Marketing \& Management, 100408. https://doi.org/10.1016/j.jdmm.2019.100408

Tejada, P., Santos, F. J., \& Guzmán, J. (2011). Applicability of Global Value Chains Analysis to Tourism: Issues of Governance and Upgrading. The Service Industries Journal, 31, 1627-1643. https://doi.org/10.1080/02642069.2010.485642

van der Zee, E., Gerrets, A.-M., \& Vanneste, D. (2017). Complexity in the Governance of Tourism Networks: Balancing between External Pressure and Internal Expectations. Journal of Destination Marketing \& Management, 6, 296-308.

Vögele, S., Rübbelke, D., Govorukha, K., \& Grajewski, M. (2020). Socio-Technical Scenarios for Energy-Intensive Industries: The Future of Steel Production in Germany. Climatic Change, 162, 1763-1778. https://doi.org/10.1007/s10584-019-02366-0

Wan, S. (2019). Research on the Mechanism and Path of Innovation Driving the Revitalization of Rural Industry. Academic Journal of Zhongzhou, No. 9, 26-32.

Wang, T., \& Kang, R. (2016). On Competitive Advantages' Forming Mechanism of Enterprise Value Networks and Its Lock-In Effect in New Economic Era. Journal of Management, 29, 35-40.

Weiermair, K. (2006). Prospects for Innovation in Tourism. Journal of Quality Assurance in Hospitality \& Tourism, 6, 59-72. https://doi.org/10.1300/J162v06n03 04

Weimer-Jehle, W. (2006). Cross-Impact Balances: A System-Theoretical Approach to Cross-Impact Analysis. Technological Forecasting and Social Change, 73, 334-361. https://doi.org/10.1016/j.techfore.2005.06.005

Weimer-jehle, W. (2014). Introduction to Qualitative Systems and Scenario Analysis Using Cross-Impact Balance Analysis (pp. 1-11). Stuttgart: Interdisciplinary Research 
Unit on Risk Governance and Sustainable Technology Development, University of Stuttgart.

Wu, L., Wu, W., \& Feng, X. (2019). Reconstruction of Rural Tourism Value Chain Leaded by Value Co-Creation. Chinese Journal of Agricultural Resources and Regional Planning, 40, 227-231.

Xie, X. (2020). New Farmer Identity: The Emergence of a Post-Productivist Agricultural Regime in China. Sociologia Ruralis. https://doi.org/10.1111/soru.12322

Yılmaz, Y., \& Bititci, U. S. (2006). Performance Measurement in Tourism: A Value Chain Model. International Journal of Contemporary Hospitality Management, 18, 341-349. https://doi.org/10.1108/09596110610665348

Zhang, X., \& Kong, X. (2020). Changes, Problems and Countermeasures in Value Chain of Agricultural Product in China. Rural Economy, No. 1, 8-15.

Zheng, L., \& Liu, H. (2014). Increased Farmer Income Evidenced by a New Multifunctional Actor Network in China. Agronomy for Sustainable Development, 34, 515-523. https://doi.org/10.1007/s13593-013-0169-2

Zheng, L., \& Ma, T. (2015). Construction of Multifunctional Agriculture Innovation Network-A Case Study of Dalishu Village. Research Agricultural Modernization, No. 4, 643-650.

Zheng, L., Li, G., Guo, Y., \& Wang, H. (2020). The Endogenous Mode of Beautiful Rural Construction: A Case of China. Journal of Human Resource and Sustainability Studies, 8, 349-370. https://doi.org/10.4236/jhrss.2020.84020

Zheng, L., Wang, H., Luo, Y., \& Zhou, X. (2019). Multifunctional Landscape Actor-Network Construction from the Perspective of Rural Tourism Experiences. Journal of Landscape Research, No. 1, 79-86. 